\title{
Application of Shield in Subway construction
}

\author{
Lixin $\mathrm{Li}^{1, \mathrm{a}}$, Huaizhong Jiang ${ }^{2, \mathrm{~b}^{*}}$ \\ ${ }^{1,2}$ Shenyang east road no. 9 Shenyang Jianzhu University, Liaoning province, China \\ a1850741854@qq.com, b992389901@qq.com \\ ${ }^{*}$ Corresponding author
}

\begin{abstract}
Keywords: Shield; Subway Construction; Tunnel; Applications
Abstract: In 21st century, with the urban population increasing, conurbation is getting more and more crowed,traffic jam happens everywhere. In this case, utilization of the underground space has become an effective way to undertake this set of problems. Subway, a kind of urban underground transport, it is convenient, with little congestion, and it can deal with large passenger flow easily .Subway has been constructed in many cities. Shield is a way of underground excavation in subway constructing .It is fast, safe, low environmental impacting and has many other advantages. So it become popular and is widely applicated. This article is for the pros and cons of Shield, about the application of the shield in subway. Also talk about advantages and shortcomes of Shield.
\end{abstract}

\section{History of Shield}

Shield originated in United Kingdom. One day a British engineer, M.I.Brunel saw a worm digged through a hull. The worms secrete liquid and sprayed it on the board of a ship. This inspired the engineer. In 1818, engineers M.I.Brunel patented Shield ${ }^{[1]}$.

In 1843, Thames underwater tunnel witch was constructed with Shield was built. It became the world's first Shield tunnel, created a Shield tunnel construction history.

At the beginning of 20th Century.France, Japan, UK, USA, Germany, the former Soviet Union and other developed countries have started research and improve Shield application.

In 1993, The Channel Tunnel, which has an outer diameter of 8.4 meters is built with Shield.

In 1997, the outer diameter of 13.9 meters Tokyo Bay highway tunnel was built. According to the statistics in 1991 in Tokyo, Osaka and other cities, the total extension of city tunnel project is 75224 meters, $60.9 \%$ of them is Shield tunnel. Shield has obvious advantage when it comes to crowed conurbation, where the impact of construction is limited ${ }^{[2]}$.

Shield has a history of nearly 200 years, and makes much progress by these years around the word. But in China, it remains blank before the founding of PRC. After the founding of New China, since 1950, China began to apply Shield on sewer construction. For example,coal mine aqueduct project in Fuxin use 2.6meter diameter Shield construction.

In 1957, Beijing sewer project tried $2.0 \mathrm{~m}$ and $2.6 \mathrm{~m}$ calibre Shield construction.

In 1963, Shanghai Tangqiao Shield tunnel began to construct. It was a representation that China began to have a system in research,design,fabrication and improve in Shield technic.

In 1966, Shanghai Shield Construction Corporation used grid shield method to build the first The Huangpu River tunnel. Henceforth, China began to have its own history of Shield tunnel.

In 1969, Beijing, the first Shield subway tunnel was built.

In 1984, Shanghai the second Huangpu River tunnel which had a diameter of 11.32 meters was completed by using Shield method.

After 1990 on the basis of introducing and absorbing foreign technology, Shield tunnel began widely applied in China's urban Subway projects, such as Shanghai, Beijing, Guangzhou, Shenyang, Chengdu, Hangzhou, Changsha and other cities.

In 2004 ,Wuhan Yangtze River Tunnel, represented that Chinese Shield research and technology had stepped into the forefront of the world .These projects above had accumulate many experiences for China's Shield tunnel, promoted the level of Chinese shield tunneling technology. 


\section{The advantages and disadvantages of Shield tunneling}

Subway shield method construction is mainly constituted by three steps: stabilizing excavation surface, digging and dumping soil, lining the tunnel wall and grouting it.

Open-cut method of urban subway constructing has many shortcomes, especially in densely populated area and business hub. When it comes to city center, with complex geological conditions and tunnel, it is impossible to use open-cut method ${ }^{[3]}$. In this condition, Shield construction method has its obvious technical and economic advantages that it causes little damage to urban ground environment ${ }^{[4]}$.

Shield construction has the following advantages

1)Safe to excavation and lining, high driving speed. It is always under the protection of a closed shield shell construction operations, basically avoiding the occurrence of high-pressure water gushing and soft soil subsidence and other major construction disasters;

2)Little affects to ground transportation and facilities, while not affecting the underground pipelines and other facilities;

3)Low labor intensity of construction Shield forward, unearthed, assembled lining and the whole process can be automated;

4)Shield has technical and economic advantage in comparatively deep long tunnel in Soft water bearing strata;

5)When across the river, Shield construction does not affect shipping. And it will not be affected by wind and rain and other weather conditions. It makes little construction noise and disturbance.

Meanwhile, Shield construction also has the following disadvantages

1)Shield machine is expensive and highly targeted ${ }^{[5]}$. It requires specially design and manufacture according to geological, hydro-geological conditions and structural section size. The machine generally can not simply be used in other tunnels reuse;

2)It is not safe enough in some underwater tunnel and shallow overburden area;

3)When use all-pneumatic method dewatering and steady soil, with poor construction condition, Shield requires high protection;

4)When the radius of curvature of the tunnel is too small or the overburden tunnel roof is too shallow it is very difficult too use Shield machine;

5)When apply to water-rich and soft soil where surface subsidence is difficult to control. It demands high water-proof technical for lining.

\section{Application in subway construction}

There are many methods in subway construction, open-cut method, cover excavation method and the tunneling method. Open-cut method has severe impacts on surroundings and ground. It produces lots of noise. So it is only suitable for area with little people, traffic and pipeline and is rarely used now. Cover excavation method also has a certain impact to the ground. With the crowding city and increasing traffic pressure, Shield, as a part of tunneling method, it is safe, fast, and has little impact to the surroundings, become more attention and widely used.

\section{In crowded urban area}

In some of the larger cities (especially metropolis, where the population density is quite big).At some large shopping malls or important crossroads, the huge daily pedestrian volume and traffic volume is a big problem for construction. If conductor use open-cut method in Subway construction in these areas, bound to heavy traffic, there will be a devastating impact to the economy, some may even lead to traffic gridlock. This time, Shield with its few impact on the ground shows a sufficient advantage. For example, Shenyang Zhong Jie subway station to the Pang Jiang Street subway station, which use shield construction, did not have much impact on ground transportation, and achieved good results.

passing through tall buildings or important buildings

Considered land subsidence, when digging through some tall buildings or important buildings, open-cut method is not suitable for construction. Excessive ground settlement will lead to more 
serious consequences. Conductor can chose Shield construction method. Such as Xianghu Subway stations in Hangzhou, metro line four. In this building process, due to the ground monitoring and management mistakes, ground subsidence happened and river poured, causing severe consequences. Shield construction can effectively control surface subsidence when constructing properly. The main point of surface subsidence control is limiting the amount of slag. The amount of slag is mainly depending on geological condition, the Shield machine and operating. Geological condition makes a direct influence on the degree of how difficult to control the amount of slag. Choosing different types and different configurations of Shield machine according to geological conditions has significantly effects in controlling the amount of slag. Meanwhile the manipulative skill of worker also contributes to the amount of slag. When digging under buildings, according to the geological conditions, contractor can choose reinforce the buildings. In order to prevent land subsidence, sometimes contractor can reinforce the ground. The establishment of observation points on the ground, on time, by volume were observed and measured, and strictly control land subsidence within the specified range.

\section{When digging through under river}

When the subway is passing through under a river ${ }^{[6]}$, we need to dig a tunnel. Shield construction will show its advantage of high digging speed. We choose Shenyang Hunnan Avenue Subway Station to Chang Qing Bridge Station as an example to illustrate the application of Shield construction when digging through under a river. In this project, the length of the tunnel is 450 meters.Depth of Hun River is 3-4 meters, the gauge height variate in 1-2 meters. The river is a hazard to the tunnel under it. How to deal with the Hun River water pressure became a major problem to this construction. To overcome this problem, contractor increased drain-pipe and water pump to reduce water pressure. Controlling proportion of the slurry to make it easy for the Shield machine to throw out mud easily. The mud threw out will cause pressure, conductor can use this pressure to balance the soil pressure and water pressure of the cut surfaces. The upper strata geological condition of the tunnel is composed by coarse sand layer but the sublayer is composed by fine sand, it increased the resistance when digged. In addition, there are many different sizes of pebble in the soil, which will easily broke the blade of Shield machine and made it difficult to dig forward. To solve these issues, conductor enhance the blade by using foreign patent technology and digged through the Hun River once for all. This construction only took nearly three months to dig a 450 meters long tunnel under Hun River, showed Shield construction has a high speed.

\section{Conclusions}

People say that the 21 st century is the century to develop underground space, so the construction of underground works will become increasingly important. As a underground construction methods, shields, with its high speed, high level of security, high automated, will become more and more popular. With the development of technology, materials (especially materials which increase blade intensity) and increasing of shield machine type, application of the Shield will be more extensive. Meanwhile, we should be aware of the following issues since the shield in China started very late:

1) So far, a great majority of the Shield machine is imports, which increase the cost of construction. In this case, China should increase investment in research and development to make its own Shield machine in order to reduce construction costs.

2) Although the construction of the Shield technology in China has made a considerable progress, but compared with foreign advanced Shield technology, there are still some gaps, such as key components material and the durability of blade are not good enough. We still need to keep researching and improving.

I believe that in near future, China's Shield technology will catch up with the word and reach the advanced level, the application of the Shield law in our country will be more extensive, more mature.

\section{Acknowledgements:}

This thesis is supported by the Natural Science Foundation of Liaoning Province Foundation. 
Item Number: 201202178

\section{References}

[1] Jianhang Liu, Xueyuan Hou.Shield Method Tunnel [M], In Chinese.Beijing,China Railway Publishing House, 1991.

[2] Haiying Zhou,Theoretical Study and Test on mechanic Behavior of Lining Segment in Shield Tunnel[D],In Chinese.Dalian Ligong University,2011

[3] Takimoto Kunihikol ,Yanachi kenichi.The State of Affairs of Large Diameter Shield Tunnel Method for Subway and the Recent Trend of Shield Technology in Japan [C]. Bangkok, Thailand, February,2006.

[4] Koyama Y.Present status and technology of shield tunneling method in Japan[J].Tunneling and underground space technology,2003,18(2):145-159.

[5] Mengshu Wang,Tunneling by TBM/shield in China:State-of-art,problems and proposals[J]In Chinese.Tunnel Contruction,vol.34,No.3,Mar.2014.

[6] Chuanhe,Jiangang Zhang,Zongxian Su,Large sections of underwater shield tunnel structure mechanical properties[M],In Chinese.Science Publishing house,BeJing,2010. 